\title{
In h alt.
}

Einleitung

Allgemeiner Teil . . . . . . . . . . . . . . . . 3

Begriff der Luxation ............. 3

Ursache................... 3

Traumatische, pathologische, congenitale Luxation.. 3

Mechanismus................. 4 4

Richtung . . . . . . . . . . . . . . . 5

Symptome, Diagnose, Prognose, Therapie v. bei den

einzelnen Luxationen............ 6

Specieller Teil . . . . . . . . . . . . . . . . 13

Luxation des Unterkiefers . . . . . . . . . . 13

a) doppelseitige .................. . . . 13

b) einseitige ................. . . 18

Luxation der Wirbel. . . . . . . . . . 19

a) Halswirbel ................... . . 19

b) Brust- und Lendenwirbel . . . . . . . . . . . . 24

Luxation des Brustbeins und der Rippen ...... 25

Luxation des Schlüsselbeins........... 27

a) am sternalen Ende............. 28

b) am acromialen Ende .............. . . 33

Luxation im Schultergelenk . . . . . . . . 36

Luxation im Ellbogengelenk............ 51

a) beider Vorderarmknochen ............. 52

b) der Ulna. . . . . . . . . . . . . . . . 61

c) des Radius.................. 62

Luxation im Handgelenk. . . . . . . . . . . 66 
Inhalt.

Luxation der Finger ............. 67

a) des Daumens ............... . . 68

b) der übrigen Finger. . . . . . . . . . . 71

Luxation im Hüftgelenk . . . . . . . . . . 73

Einteilung............. 74

a) Luxatt. posticae . . . . . . . . . . . . 76

b), anticae ............. 84

c) Luxat. supraglenoidalis .............. . . 91

d), infraglenoidalis . . . . . . . . . . .993

e), centralis . . . . . . . . . . . 94

Luxation im Kniegelenk . . . . . . . . . . 95

Luxation der Patella............. 102

Luxation im Fussgelenk ............ 106

a) im Talocrural-Gelenk . . . . . . . . . . . . 107

b) im Talotarsal-Gelenk . . . . . . . . . . . . . 118

c) im Talocrural- und Talotarsal-Gelenk ........ 123

Luxation der vorderen Fusswurzelknochen und im Me-

tatarsotarsal-Gelenk ............ 127

Luxation der Zehen.............. . . 129 